\title{
The Meteorological
}

Society of

Japan

Scientific Online Letters on the Atmosphere (SOLA)

\section{EARLY ONLINE RELEASE}

This is a PDF of a manuscript that has been peer-reviewed and accepted for publication. As the article has not yet been formatted, copy edited or proofread, the final published version may be different from the early online release.

This pre-publication manuscript may be downloaded, distributed and used under the provisions of the Creative Commons Attribution 4.0 International (CC BY 4.0) license. It may be cited using the $\mathrm{DO}$ below.

The DOI for this manuscript is

DOI: 10.2151/sola. 2021-027.

J-STAGE Advance published date: July 28, 2021

The final manuscript after publication will replace the preliminary version at the above DOI once it is available. 


\section{Effects of Anomalous Arctic Polar Vortex on Vegetation Growth in Northern Eurasia}

1 National Ecosystem Science Data Center, Key Laboratory of Ecosystem Network Observation and Modeling, Institute of Geographic Sciences and Natural Resources Research, Chinese Academy of Sciences, Beijing 100101, China

2 State Key Laboratory of Loess and Quaternary Geology, Institute of Earth Environment, Chinese Academy of Sciences, Xi'an, Shaanxi, China

*Corresponding author. E-mail: huangm@igsnrr.ac.cn 17 


\section{Abstract}

The northern Eurasia is a region heavily affected by the Arctic polar vortex (APV). Understanding the vegetation responses to anomalous APV in this region is important for dealing with climate change. In this study, we investigated the impacts and mechanism of the anomalous APV phases on the vegetation dynamics in the northern Eurasia. The larger and smaller APV phases correspond to almost opposite atmospheric circulation patterns which result in opposite vegetation responses. The decreased (increased) solar radiation, the enhanced (weakened) northerly winds, together with the decreased (increased) water vapor divergence, caused the decreasing (increasing) of the air temperature, increasing (decreasing) of the precipitation and soil moisture in the study area during the larger (smaller) APV phase. The response of vegetation growth to the APV depends on climate change and vegetation sensitivity to it. In most parts of the study area, vegetation growth was positively associated with air temperature, and hence, vegetation was suppressed (promoted) during the larger (smaller) APV phase. In the northeast of the Caspian Sea (NCS), vegetation growth was sensitive to precipitation. Therefore, the increased (decreased) soil moisture in summer and autumn were responsible for the promoted (suppressed) vegetation growth during the larger (smaller) APV phase.

Key word: Arctic polar vortex, NDVI, sensitivity, vegetation, Eurasia

\section{Introduction}

The Arctic polar vortex (APV) is a vortex system located in both troposphere and the stratosphere over the Arctic pole, and it can extend horizontally to the mid-high latitude area (Liu et al., 2020). The changing APV caused changes in weather regimes, and resulted in great temperature and precipitation changes in local and mid-latitude (Mitchell, et al., 2013). Studies have shown that the weakened intensity of the APV over the past decades were strongly associated with the Arctic Amplification (Zhang et al., 2016). The wavier of the APV allowed cold polar air more likely to move into the middle latitudes, and resulted in more frequent weather extremes (Francis \& Vavrus, 2012; Walsh, 2014; Francis \& Skific, 2015; Shepherd, 2016; Cohen et al., 2020). Climate is the major factor influencing vegetation growth. The 
variation of the APV had great impacts on climate in high and middle latitudes, but its impacts on vegetation growth is still unclear.

The northern Eurasia is a region close to the Arctic Ocean. Previous studies in the northern Eurasia mainly focus on two aspects, the influence of the APV on climate factors (Kogan, 1995; Shen et al., 2012; Zhang et al., 2016) and the influence of climate factors on vegetation growth (Myneni et al., 1997; Tucker et al., 2001; Tape et al., 2006; Bunn et al., 2007; Bhatt et al., 2010). Some studies associated the vegetation dynamics in the northern Eurasia with climate dynamics (Gong and Shi 2003; Gouveia et al., 2008; Li et al., 2016; Li et al., 2017), but only Li et al. (2017) related the vegetation dynamics with the APV. Li et al. (2017) explored the effect of preceding wintertime APV on springtime NDVI patterns using snow melting to explain the mechanism, but they did not discuss the simultaneous APV effects on NDVI. The APV is an important climate system in the northern Eurasia, but its direct impact on the vegetation dynamics and the mechanism are still unclear. Therefore, it is important to understand the response of vegetation activities to anomalous APV in the northern Eurasia.

In this paper, we discussed the impacts of the anomalous APV on vegetation growth in the northern Eurasia, using an APV index (APVI) to represent the space extend of the APV, and the Normalized Difference Vegetation Index (NDVI) to represent vegetation growth. The objectives of this study are (1) to assess the responses of temperature, precipitation, atmospheric circulation and vegetation growth to the anomalous APV in the northern Eurasia; 2) to discuss the mechanism of the anomalous APV impacts on vegetation dynamics and 3) to explore the vegetation sensitivity to climate change and relate it to vegetation types and their response to climate variability.

\section{Materials and Methods}

\subsection{Study area}

In this study, the northern Eurasia is defined as in between $10^{\circ} \mathrm{W}-66^{\circ} \mathrm{E}$ and $36^{\circ} \mathrm{N}-72^{\circ} \mathrm{N}$, which includes Europe continent and adjacent Asian region. Croplands, mixed forests, evergreen needleleaf forests and grasslands are major vegetation types in the study area, each occupied $38.2 \%, 16.8 \%, 16.3 \%$ and $9.9 \%$ of the vegetated area, respectively. Grasslands mainly 
distributed in the south of the Black Sea and in the north and northeast of the Caspian Sea (Fig.1).

\section{Figure 1}

\subsection{APVI Calculation}

We used the APVI to represent the variation of the APV. The spatial extent of the APV at $500 \mathrm{hPa}$ is defined as the area surrounded by the southern boundary characteristic contour line, $\mathrm{H}_{0}$, which is established based on geopotential height in the Northern Hemisphere (Zhang et al., 2008; Sui et al., 2014). The monthly area of the APV is:

$S_{m}=\int_{\varphi_{0}}^{\frac{\pi}{2}} \int_{0}^{2 \pi} R^{2} \cos \varphi d \varphi d \lambda$

where $\varphi_{0}$ is the latitude of $\mathrm{H}_{0}$ (560 dagpm), $\varphi$ and $\lambda$ is the latitude and longitude of the point in the APV, the unit is radian. $R$ is the radius of the earth $(R=6378 \mathrm{~km})$.

We define $S$ as the average of monthly $S_{m}$ through the year, then APVI is:

$A P V I=\frac{S}{10^{5} \mathrm{~km}^{2}}$

We used 0.75 standard deviation as the threshold to define the extreme APVI years. A year with its APVI anomalies greater than 0.75 standard deviation was defined as a larger APVI year, and a year with its APVI anomalies less than -0.75 standard deviation was defined as a smaller APVI year. During the study period, the larger APVI years are 1984, 1985, 1992, 1993, 1996 and 1997, and the smaller APVI years are 1989, 2005, 2012, 2013, 2014 and 2015.

\subsection{Vegetation Data}

The NDVI data with a spatial resolution of $1 \mathrm{~km} \times 1 \mathrm{~km}$ from 1982 to 2015 were obtained from the Global Inventory Modeling and Mapping Studies (GIMMS 3g), which were free access from NASA earth data website (https://ecocast.arc.nasa.gov/data/pub/gimms/3g.v1) (Tucker et al., 2005; Pinzon \& Tucker, 2014). In this study, we identify vegetation as NDVI values greater than 0.1 (Zhou et al., 2003). The vegetation type maps were obtained from MODIS datasets of MOD12Q1, free access at https://modis.gsfc.nasa.gov/. 


\subsection{Climate data}

The wind speed and geopotential height data, with the spatial resolution of $2.5^{\circ} \times 2.5^{\circ}$ and the data period of 1982-2015, were from the NCEP/NCAR reanalysis project, free access at https://psl.noaa.gov/data/reanalysis/reanalysis.shtml (Kalnay et al., 1996). The monthly mean air temperature and precipitation, with the spatial resolution of $0.5^{\circ} \times 0.5^{\circ}$ and the data period of 1982 to 2015, were from Climate Research Unit (CRU, http://www.cru.uea.ac.uk/). The surface solar radiation, volumetric soil water in $0-7 \mathrm{~cm}$ soil depth, vertical integral of water vapor flux and its divergence with the spatial resolution of $0.25^{\circ} \times 0.25^{\circ}$ were obtained from ERA5 project (Hersbach et al, 2019), free access at https://cds.climate.copernicus.eu/cdsapp\#!/dataset/reanalysis-era5-single-levels-monthlymeans? tab $=$ overview.

\subsection{Statistical methods}

Correlation analysis was used to analysis the relationship between NDVI and APVI, and the Student's t test was used to test the significant level. Composite analysis, which has been widely used in climate research (Rudeva \& Gulev, 2011), was used to average the anomalies of variables, such as NDVI, temperature, precipitation, geopotential height and wind speed, over the larger and smaller APVI years. All anomalies used in this study were relative to the mean of 1982-2015. Sensitivity analysis was used to investigate the individual contributions of temperature and precipitation anomalies to NDVI anomalies using Eq. 3 (Kim et al., 2017).

$\delta(N D V I)=\frac{\partial(N D V I)}{\partial(\text { Temp })} \delta($ Temp $)+\frac{\partial(N D V I)}{\partial(\text { Prec })} \delta($ Prec $)+\varepsilon$

$=\gamma_{N D V I}^{\text {Temp }} \delta($ Temp $)+\gamma_{N D V I}^{\text {Prec }} \delta($ Prec $)+\varepsilon$

where $\gamma_{N D V I}^{\text {Temp }}$ and $\gamma_{N D V I}^{\text {Prec }}$ are the coefficients of partial regression method, which reflect the sensitivities of NDVI to surface temperature and precipitation, respectively. Student's t-test was used to test the confidence level.

\section{Results}

\subsection{Effects of anomalous APV on atmospheric circulations}

The geopotential height fields at 500hPa for the larger APV phase was almost opposite to that 
for the smaller APV phase. Negative and positive geopotential height anomalies covered most of the study areas during the larger and smaller APV phases, respectively. There is a maximum geopotential height anomaly center over the Norwegian Sea during the larger, but a minimum geopotential height anomaly center occurred in the same place for the smaller APV phase (Fig. $2 a, 2 b)$.

The wind speed anomaly at $1000 \mathrm{hPa}$ for the larger APV phase was almost opposite to that for the smaller APV phase. The northerly winds were strengthened, especially in the area west of $30^{\circ} \mathrm{E}$, during the larger APV phase, which implies the cold Arctic air was more likely to flow southward and decreased air temperature in the study area (Fig. 2c). In contrast, the southerly winds were strong in most parts of the study area, especially in the west of $30^{\circ} \mathrm{E}$, during the smaller APV phase, which was conducive to the northward inflowing of the warm air and resulted in the increasing of the air temperature (Fig. 2d).

There are apparent differences between the spatial patterns of the water vapor flux and its divergence for the larger and smaller APV phases (Fig. 2e, 2f). In the north of the Black Sea and the Caspian Sea, the southerly and northerly water vapor fluxes respectively occurred in the larger and smaller APV phases, while the negative and positive water vapor divergence anomalies respectively occurred in the larger and smaller APV phase. The negative water vapor divergence anomalies were conducive to precipitation formation. The positive water vapor divergence anomalies, which dominant most areas of the study area during the smaller APV phase, were not conducive to precipitation formation.

\section{Figure 2}

\subsection{Effects of anomalous APV on climatic factors}

The distributions of surface air temperature anomalies for the larger APV phase are also opposite to corresponding anomalies for the smaller APV phases. Negative and positive temperature anomalies covered all of the northern Eurasia continent during the larger and smaller APV phase, respectively (Fig. 3a, 3b). The study area mean air temperature anomalies for the larger and smaller APV phase were $-0.65^{\circ} \mathrm{C}$ and $0.62^{\circ} \mathrm{C}$, respectively. 
Most of the downwelling surface shortwave radiation anomalies were negative and positive during the larger and smaller APV phases, respectively (Fig. 3e, 3f), which were generally consistent with the spatial pattern of the air temperature anomalies in corresponding phases. The negative solar radiation anomalies accounts for $80.5 \%$ of the terrestrial area during the larger APV phase, but that only accounts for $13.5 \%$ of the terrestrial area during the smaller APV phase. The study area mean solar radiation anomalies are $-1.2 \times 10^{5} \mathrm{~J} \mathrm{~m}^{-2}$ and $1.5 \times 10^{5} \mathrm{~J} \mathrm{~m}^{-}$ ${ }^{2}$ for the larger and smaller APV phase, respectively.

The study area mean precipitation anomalies for the larger and smaller APV phase were $15.5 \mathrm{~mm}$ and $0.85 \mathrm{~mm}$, respectively (Fig.3c, 3d). During the larger APV phase, negative precipitation anomalies occurred in $75.4 \%$ of the study area, with the minimum of $-489 \mathrm{~mm}$, while positive anomalies only occurred in $24.6 \%$ of the study area, with the maximum of $138 \mathrm{~mm}$. During the smaller APV phase, negative anomalies occurred in 53.3\% of the study area, with the minimum of $-123 \mathrm{~mm}$, while positive anomalies occurred in $46.7 \%$ of the study area, with the maximum of $362 \mathrm{~mm}$.

The spatial patterns of the volumetric soil water (within the soil depth of $0-7 \mathrm{~cm}$ ) anomaly for the larger and smaller APV phases were almost opposite. Positive and negative anomalies occurred in $64.4 \%$ and $74.8 \%$ of the study area during the larger and smaller APV phase, respectively (Fig. 3g, 3h). Higher positive and lower negative soil water anomalies were mainly located in the north of the Black Sea and Caspian Sea during the larger and smaller APV phase, respectively.

\section{Figure 3}

\subsection{Effects of anomalous APV on NDVI}

Vegetation growth were suppressed and promoted during the larger and smaller APV phases, respectively. During the larger APV phase, negative yearly mean NDVI anomalies occurred in $82.5 \%$, while positive anomalies occurred in $17.5 \%$ of the vegetated area (Fig. $4 a$ ). The study area mean NDVI anomalies were -0.01 . However, the study area mean NDVI anomalies were 0.01 during the smaller APV phase (Fig. 4b). Negative NDVI anomalies only occurred in $36.8 \%$ 
of the vegetated area, with the minimum of -0.20 , while positive anomalies occurred in $63.2 \%$ of the vegetated area, with the maximum of 0.23 .

\section{Figure 4}

Spring mean NDVI has the strongest association with the APV (Fig.5). The correlation coefficients between APVI and regional mean spring (March to May), summer (June to August), autumn (September to November) and winter (January, February and December) mean NDVI are $-0.50,-0.32,-0.34,-0.45$, respectively. Composite analysis of the seasonal mean NDVI anomalies also confirm this conclusion (Fig. 6). The study area mean spring, summer, autumn and winter NDVI anomalies are $-0.024,-0.002,-0.0086$ and -0.014 for the larger APV phase, and $0.01,0.002,0.0067$ and -0.0002 for the smaller APV phase, which implies the spring has the highest NDVI differences between the larger and smaller APV phases.

\section{Figure 5}

\section{Figure 6}

\section{Discussion}

\subsection{Sensitivity of NDVI to temperature and precipitation change}

The response of vegetation growth to the anomalous APV phases depends not only on the APVinduce temperature and precipitation anomalies but also on the sensitivity of vegetation to climate anomalies. Studying the sensitivity of NDVI to temperature and precipitation change is a critical step for understanding the physical mechanism of vegetation response to the anomalous APV phase.

Most of the NDVI values in the study area were sensitive to air temperature (Fig. 7a). The temperature coefficients averaged for crops, mixed forests, evergreen needleleaf forests and grasslands were $0.011,0.014,0.013$ and 0.005 , respectively, which implies vegetation growth were positively associated with air temperature in the northern Eurasia. This association between temperature and NDVI was consistent with many other's researches (Myneni et al., 
1997; Tucker et al., 2001;Bunn et al., 2007; Li et al., 2016).

The NDVI responses to precipitation was not consistent throughout the region. Both positive and negative sensitivity coefficients occurred in the study area (Fig. 7b). The mean precipitation coefficients for crops, mixed forests, evergreen needleleaf forests were approach to zero, which implies crops and forests may not associate with precipitation in the study area. The sensitivity of grasslands to precipitation is complex. Grasslands mainly distributed in the south of the Black Sea (SBS) and the northeast of Caspian Sea (NCS). Grasslands in (SBS) were more sensitive to air temperature than precipitation, with mean temperature coefficients of 0.01 and mean precipitation coefficients approach to zero. However, that in the NCS were less sensitive to air temperature than precipitation, with mean temperature coefficients of 0.001 and mean precipitation coefficients of 0.002 . This implies that the sensitivity of vegetation to climate factors not only depends on the vegetation type, but also depends on where the vegetation is located.

The different precipitation sensitivity between grasslands in SBS and NCS could be interpreted as the local climate and the grasslands difference between the SBS and NCS. The annual total precipitation in the SBS were between $200-400 \mathrm{~mm}$, but that in the NCS were about $100 \mathrm{~mm}$. The secondary classification for grasslands in the SBS is temperate steppe, but in the NCS is desert steppe. The temperate steppe in the humid climate of the SBS may not limited by water, but the desert steppe in the semiarid to arid climate of the NCS is water limited.

\subsection{Physical mechanism of the APV effects}

The physical mechanism of the APV impacts on vegetation dynamics could be generally explained as that the anomalous APV changed the atmospheric circulation, which caused anomalous solar radiation, air temperature, precipitation and soil moisture, and resulted in changing NDVI values in the study area. Links between the APV and NDVI during the larger and smaller APV phase could be interpreted as following. 
During the larger APV phase, the solar radiation was decreased. Meanwhile, the atmospheric circulation was conducive to the southwards flow of the Arctic cold air, which caused the decreasing of the air temperature in four seasons in the study area (Fig. S1). Since NDVI values in most parts of the study area were positively associated with air temperature, the decreasing air temperature resulted in decreased NDVI in most parts of the study area except for the NCS. In the NCS, NDVI values were positively associated with precipitation. Positive soil water anomalies in the NCS (Fig.3g), especially in the summer and autumn, which were responsible for the increasing of the NDVI in this region (Fig. S2). The APV is an atmospheric phenomenon mainly in the winter and spring, and its connections with soil moisture in the summer and autumn may relate with the delayed effects of the snow cover. In the NCS, the snowfall depth were higher during the larger APV phase relative to the smaller APV phase, which caused more snow melting into the soil and increased the soil water content in the following seasons during the lager APV phase (Fig. S3).

During the smaller APV phase, the atmospheric circulation patterns were almost opposite to that of the larger APV phase. So the changes of solar radiation, temperature, precipitation and soil water content were almost opposite to those for the larger APV phase. Therefore, NDVI changed in opposite direction, that is, increased in most parts of the study area but decreased in the NCS.

\section{Conclusions}

In this study, we explored the impacts of the anomalous APV on vegetation growth in the northern Eurasia and discussed the mechanism. We found that the larger and smaller APV phases induced almost opposite anomalous atmospheric circulation patterns, which resulted in nearly the opposite solar radiation, temperature, precipitation, water vapor flux, soil water content and NDVI anomalies in the study area. During the larger APV phase, solar radiation was decreased. Meanwhile, the northerly winds were enhanced, which improved the inflowing of polar cold air to the northern Eurasia, and decreased air temperature there. During the smaller APV phase, the air temperature was increased due to the increased solar radiation and weakened 
northerly wind.

The effects of the anomalous APV on vegetation growth in the northern Eurasia not only depends on the climate variability induced by the anomalous APV, but also on the vegetation sensibility to climate factors. In most parts of the study area, vegetation growth was positive associated with air temperature, and hence, it was suppressed and promoted during the larger and smaller APV phases, respectively. In the arid and semiarid area like the NCS, vegetation growth was positive associated with soil water availability. Since the larger and smaller APV phase correspond to increasing and decreasing summer and autumn soil water content in the NCS, respectively. Vegetation growth was promoted and suppressed during the larger and smaller APV phases, respectively.

As global warming is expected to continue in the future (IPCC, 2018), vegetation will continue to beneficial from global warming in most parts of the northern Eurasia in the future. However, the warming corresponds to decreased precipitation and soil water availability in the NCS, and grasslands in the NCS will face more threats.

\section{Acknowledgments}

We would like to thank the editor and reviewers for their valuable comments and suggestions. We thank the scientific teams for Climatic Research Unit (University of East Anglia) and NCAS, NASA, the NCEP/NCAR Reanalysis Project and ERA5 Project. We would like to thank these agencies for providing the data for our work. And this study is supported by the Strategic Priority Research Program (XDA20010202), the Science and Technology Basic Resources Investigation Program of China (2017FY101301), the National Key Research and Development Program of China (2017YFC0503905), the Chinese National Natural Science Fund $(41971135,41801082)$, the Open Foundation for State Key Laboratory of Loess and Quaternary Geology (grant SKLLQG1835). 


\section{Supplements}

Supplement 1: Supplement figure S1, S2 and S3.

\section{References}

Bhatt, U. S., D. A. Walker, M. K. Raynolds, J. C. Comiso, H. E. Epstein, G. Jia, R. Gens, J. E. Pinzon, C. J. Tucker, C. E. Tweedie, and P. J. Webber 2010: Circumpolar Arctic Tundra Vegetation Change Is Linked to Sea Ice Decline, Earth Interactions, 14, doi:10.1175/2010ei315.1.

Bunn, A. G., S. J. Goetz, J. S. Kimball, and K. Zhang 2007: Northern high-latitude ecosystems

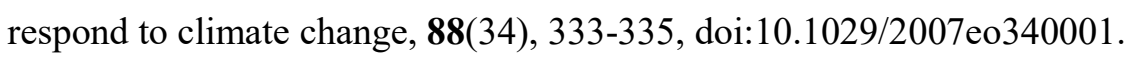

Cohen, J., X. Zhang, J. Francis, T. Jung, R. Kwok, J. Overland, T. J. Ballinger, U. S. Bhatt, H. W. Chen, D. Coumou, S. Feldstein, H. Gu, D. Handorf, G. Henderson, M. Ionita, M. Kretschmer, F. Laliberte, S. Lee, H. W. Linderholm, W. Maslowski, Y. Peings, K. Pfeiffer, I. Rigor, T. Semmler, J. Stroeve, P. C. Taylor, S. Vavrus, T. Vihma, S. Wang, M. Wendisch, Y. Wu, and J. Yoon 2020: Divergent consensuses on Arctic amplification influence on midlatitude severe winter weather, Nature Climate Change, 10(1), 20-27, doi:10.1038/s41558-019-0662-y.

Francis, J., and N. Skific 2015: Evidence linking rapid Arctic warming to mid-latitude weather patterns, Philosophical Transactions of the Royal Society a-Mathematical Physical and Engineering Sciences, 373(2045), doi:10.1098/rsta.2014.0170.

Francis, J., and S. Vavrus 2012: Evidence linking Arctic amplification to extreme weather in mid-latitudes, Geophysical Research Letters, 39, doi:10.1029/2012g1051000.

Gong, D., and P. Shi 2003: Northern hemispheric NDVI variations associated with large-scale climate indices in spring, International Journal of Remote Sensing, 24(12), 2559-2566.

Gouveia, C., R. M. Trigo, C. C. DaCamara, R. Libonati, and J. M. C. Pereira 2008: The North Atlantic Oscillation and European vegetation dynamics, International Journal of Climatology, 28(14), 1835-1847, doi:10.1002/joc.1682.

Hersbach, H., Bell, B., Berrisford, P., Biavati, G., Horányi, A., Muñoz Sabater, J., Nicolas, J., Peubey, C., Radu, R., Rozum, I., Schepers, D., Simmons, A., Soci, C., Dee, D., Thépaut, J-N. 2019: ERA5 monthly averaged data on single levels from 1979 to present, Copernicus 
Climate Change Service (C3S) Climate Data Store (CDS). doi:10.24381/cds.f17050d7

IPCC, 2018: Global Warming of $1.5^{\circ} \mathrm{C}$. (Available online at: https://www.ipcc.ch/sr15/)

Kalnay, E., M. Kanamitsu, R. Kistler, W. Collins, D. Deaven, L. Gandin, M. Iredell, S. Saha, G. White, and J. Woollen 1996: The NCEP/NCAR 40-year reanalysis project, Bulletin of the American meteorological Society, 77(3), 437-471.

Kim, J.-S., J.-S. Kug, S.-J. Jeong, D. N. Huntzinger, A. M. Michalak, C. R. Schwalm, Y. Wei, and K. Schaefer 2017: Reduced North American terrestrial primary productivity linked to anomalous Arctic warming, Nature Geoscience, 10(8), 572-580, doi:10.1038/ngeo2986.

Kogan 1995: Droughts of the late 1980s in the united states as derived from noaa polar-orbiting satellite data, Bulletin of the American Meteorological Society, 76(5), 655-668.

Li, J., K. Fan, J. Xu, A. M. Powell, Jr., and F. Kogan 2017: The effect of preceding wintertime Arctic polar vortex on springtime NDVI patterns in boreal Eurasia, 1982-2015, Climate Dynamics, 49(1-2), 23-35, doi:10.1007/s00382-016-3324-z.

Li, J., K. Fan, and Z. Xu 2016: Links between the late wintertime North Atlantic Oscillation and springtime vegetation growth over Eurasia, Climate Dynamics, 46(3-4), 987-1000, doi:10.1007/s00382-015-2627-9.

Liu, Y., Z. Wei, G. Chen, Y. Liu, X. Zhu, and Z. Zheng 2020: Shift of the Arctic polar vortex in recent decades and its simulation by the NCEP CFSv2, Physics and Chemistry of the Earth, 115, doi:10.1016/j.pce.2019.102823.

Mitchell, D. M., L. J. Gray, J. Anstey, M. P. Baldwin, and A. J. Charlton-Perez 2013: The Influence of Stratospheric Vortex Displacements and Splits on Surface Climate, Journal of Climate, 26(8), 2668-2682, doi:10.1175/jcli-d-12-00030.1.

Myneni, R. B., C. D. Keeling, C. J. Tucker, G. Asrar, and R. R. Nemani 1997: Increased plant growth in the northern high latitudes from 1981 to 1991, Nature, 386(6626), 698-702, doi:10.1038/386698a0.

Pinzon, J. E., and C. J. Tucker 2014: A Non-Stationary 1981-2012 AVHRR NDVI3g Time Series, Remote Sensing, 6(8), 6929-6960.

Rudeva, I., and S. K. Gulev 2011: Composite Analysis of North Atlantic Extratropical Cyclones in NCEP-NCAR Reanalysis Data, Monthly Weather Review, 139(5), 1419-1446, doi:10.1175/2010mwr3294.1. 
Shen B, Lian Y, Zhang S, Li S 2012: Impacts of Arctic Oscillation and Polar Vortex Anomalies on Winter Temperature over Eurasian Continent, Progressus Inquisitiones de Mutatione Climatis, 8(6), 434-439.

Shepherd, T. G. 2016: Effects of a warming Arctic, Science, 353(6303), 989-990, doi:10.1126/science.aag2349.

Sui, C., Z. Zhang, Y. Cai, and H. Wu 2014: Using the physical decomposition method to study the effects of Arctic factors on wintertime temperatures in the Northern Hemisphere and China, Advances in Polar Science(4), 213-221.

Tape, K., M. Sturm, and C. Racine 2006: The evidence for shrub expansion in Northern Alaska and the Pan-Arctic, Global Change Biology, 12(4), 686-702, doi:10.1111/j.13652486.2006.01128.x.

Tucker, C., J. Pinzon, M. Brown, D. Slayback, E. Pak, R. Mahoney, E. Vermote, and N. El Saleous 2005: An extended AVHRR 8-km NDVI dataset compatible with MODIS and SPOT vegetation NDVI data, International Journal of Remote Sensing, 26(20), 4485-4498, doi:10.1080/01431160500168686.

Tucker, C. J., D. A. Slayback, J. E. Pinzon, S. O. Los, R. B. Myneni, and M. G. Taylor 2001: Higher northern latitude normalized difference vegetation index and growing season trends from 1982 to 1999, International journal of biometeorology, 45(4), 184-190.

Walsh, J. E. 2014: Intensified warming of the Arctic: Causes and impacts on middle latitudes, Global and Planetary Change, 117, 52-63, doi:10.1016/j.gloplacha.2014.03.003.

Zhang, H., R. Jin, and Y. Zhang 2008: Relationships between summer Northern Polar Vortex with subtropical high and their influence on precipitation in North China, Journal of Tropical Meteorology, 24(4), 417-422.

Zhang, J., W. Tian, M. P. Chipperfield, F. Xie, and J. Huang 2016: Persistent shift of the Arctic polar vortex towards the Eurasian continent in recent decades, Nature Climate Change, 6(12), 1094-1099, doi:10.1038/nclimate3136.

Zhou, L., R. K. Kaufmann, Y. Tian, R. B. Myneni, and C. J. Tucker 2003: Relation between interannual variations in satellite measures of northern forest greenness and climate between 1982 and 1999, Journal of Geophysical Research-Atmospheres, 108(D1), doi:10.1029/2002jd002510. 


\section{List of Figure Captions}

Figure 1 Vegetation type maps of the study area.

Figure 2 Spatial distribution of composite wind speed (in m/s), geopotential height (in gpm), vertical integral of water vapor flux (in $\mathrm{kgm}^{-1} \mathrm{~s}^{-1}$ ) and its divergence (in $\mathrm{kgm}^{-2} \mathrm{~s}^{-1}$ ). (a) wind speed and geopotential height at 500hPa for the larger APVI years; (b) as (a) but for the smaller APVI years; (c) as (a) but at 1000hpa; (d) as (b) but at $1000 \mathrm{hPa}$; (e) vertical integral of water vapor flux and its divergence for the larger APVI years; (d) as (e) but for the smaller APVI years.

Figure 3 Composite analysis of yearly mean air temperature (in degree), yearly total precipitation (in $\mathrm{mm}$ ), surface solar radiation (in $10^{5} \mathrm{~J} / \mathrm{m}^{2}$ ) and volumetric soil water in $0-7 \mathrm{~cm}$ soil depth (in $\mathrm{m}^{3} / \mathrm{m}^{3}$ ) for the larger and smaller APVI years. (a) temperature for the larger APVI years; (b) temperature for the smaller APVI years; (c) precipitation for the large APVI years; (d) precipitation for the smaller APVI years; (e) solar radiation for the larger APVI years; (f) solar radiation for the smaller APVI years; (g) volumetric soil water for the large APVI years and (h) volumetric soil water for the smaller APVI years.

Figure 4 Spatial pattern of composite NDVI anomalies for the (a) larger and (b) smaller APVI years. The solid blue and red lines are the south boundary of the APV averaged over the larger and smaller APVI years, respectively. The dash blue line in (a) represents the mean south boundary of the smaller APV and the dash red line in (b) represents that of the larger APV.

Figure 5 Spatial distribution of correlation coefficients between APVI and seasonal mean NDVI. (a) Spring (March to May); (b) Summer (June to August); (c) Autumn (September to November) and (d) winter (January, February and December).

Figure 6 Spatial pattern of composite seasonal mean NDVI anomalies for the larger and 
smaller APVI years. (a) Spring (March to May) for the larger APVI years; (b) As (a) but for the smaller APVI years; (c) Summer (June to August) for the larger APVI years; (d) As (c) but for the smaller APVI years; (e) Autumn (September to November) for the larger APVI years; (f) As (e) but for the smaller APVI years; (g) Winter (January, February and December) for the larger APVI years and (h) as (g) but for the smaller APVI years.

Figure 7 Spatial distribution of NDVI sensitivity coefficients for (a) temperature and (b) precipitation. Regions passed 95\% confidence level is masked by black points. 


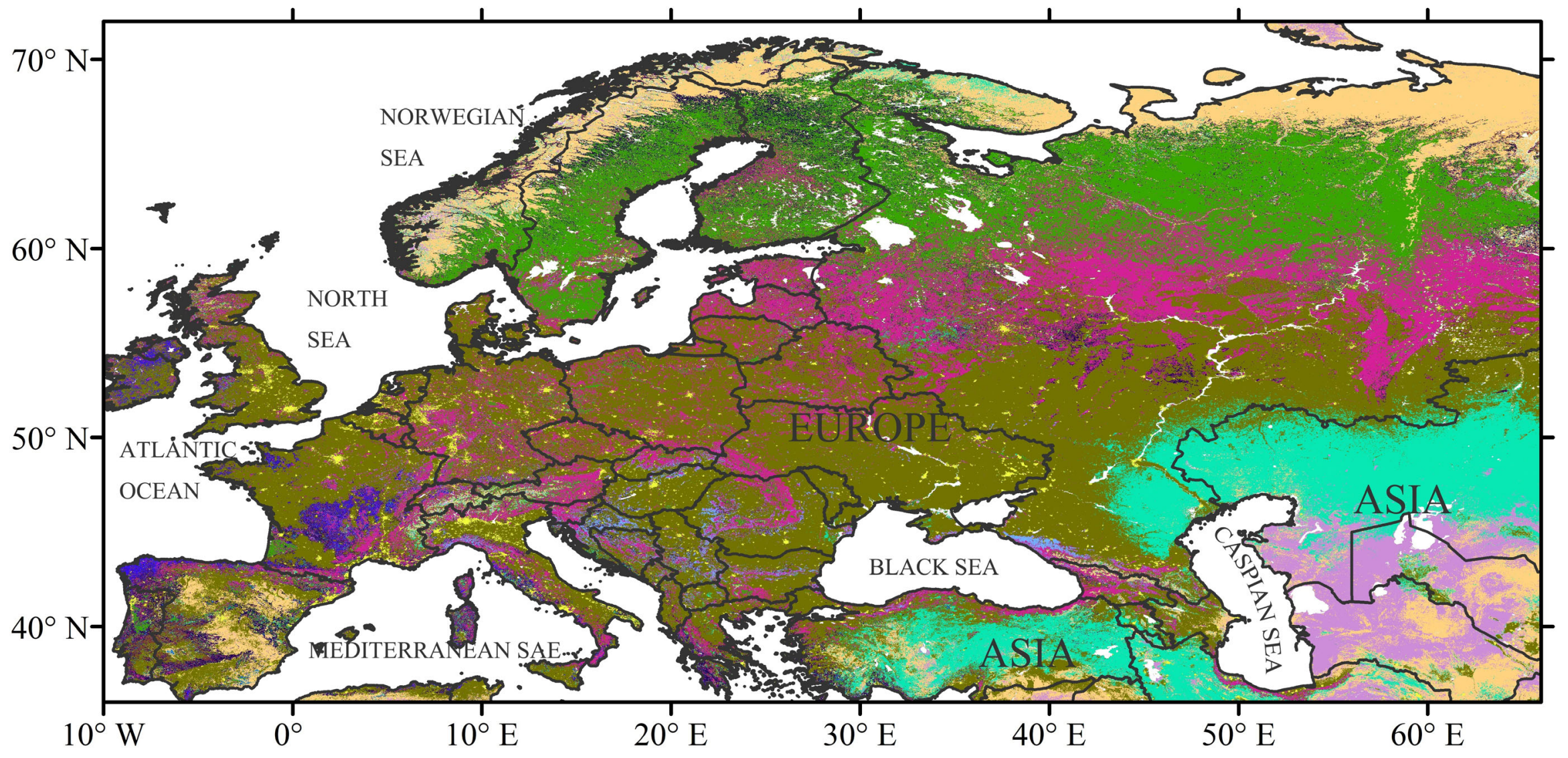

\begin{tabular}{|c|c|c|c|}
\hline water & deciduous broadleaf forest & woody savannas & urban and built-up \\
\hline evergreen needleleaf forest & mixed forests & savannas & barren or sparsely vegetated \\
\hline evergreen broadleaf forest & closed shrublands & grasslands & unclassfied \\
\hline deciduous needleleaf forest & open shrublands & croplands & \\
\hline
\end{tabular}

Figure 1 Vegetation type maps of the study area. 
(a)

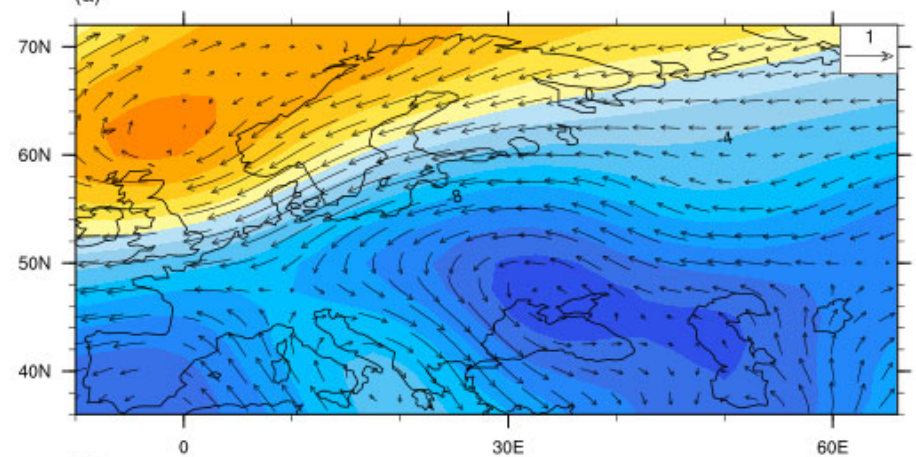

(c)
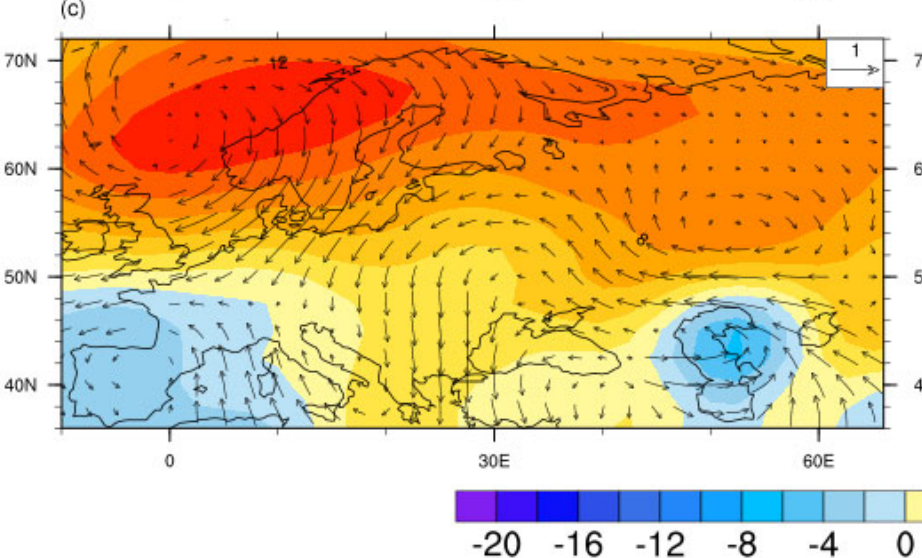

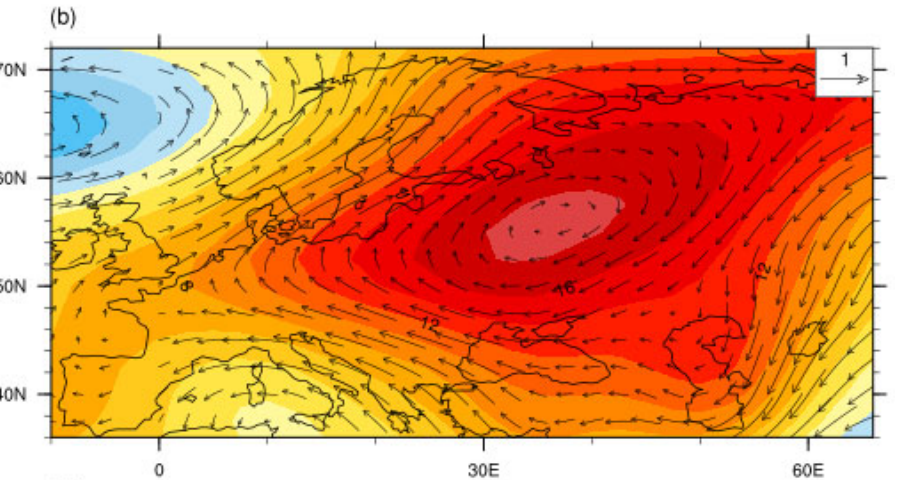

(d)

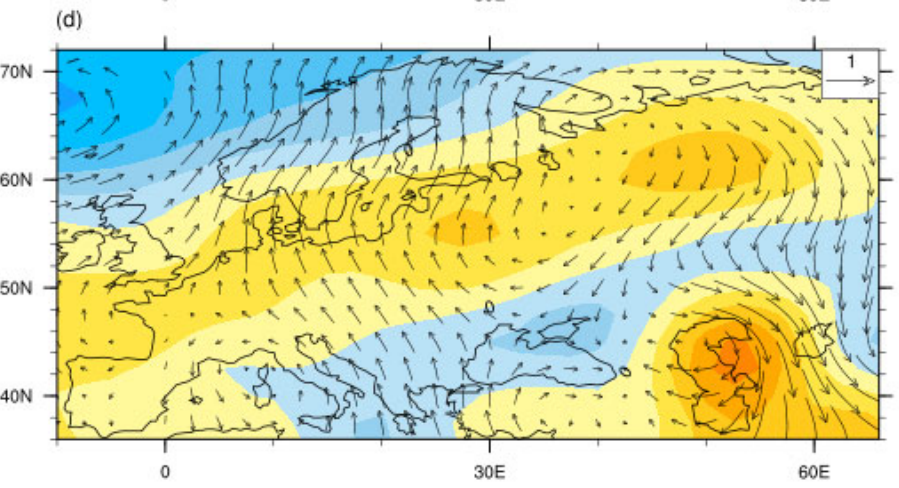

$60 \mathrm{E}$

(e)

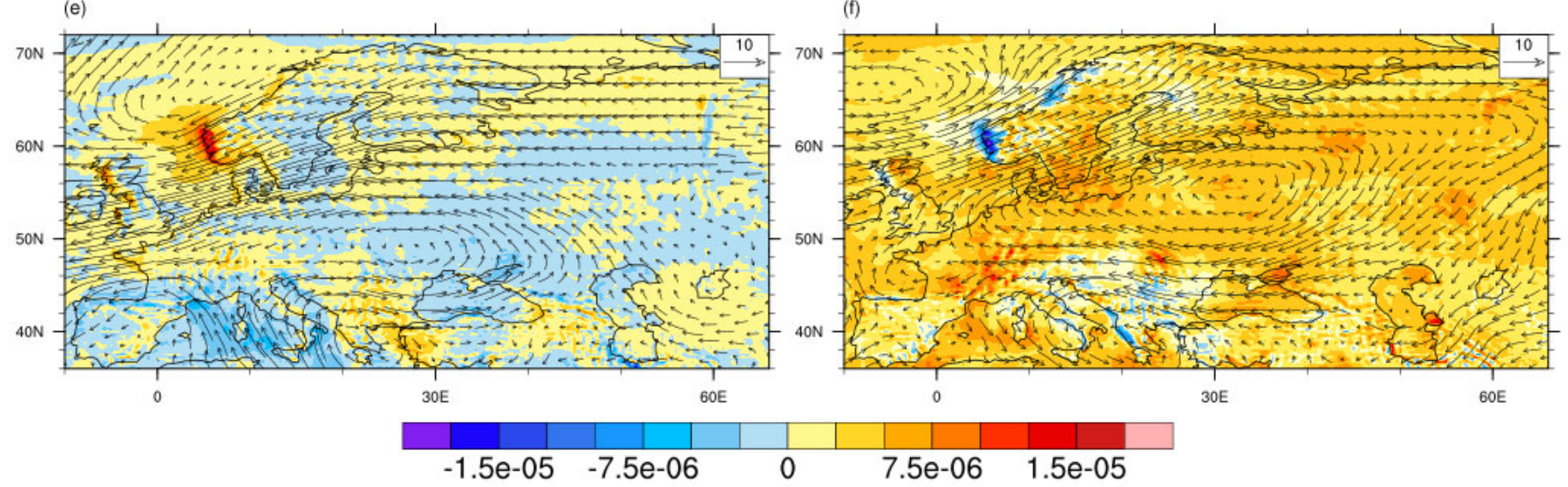

Figure 2 Spatial distribution of composite wind speed (in $\mathrm{m} / \mathrm{s}$ ), geopotential height (in gpm), vertical integral of water vapor flux (in $\mathrm{kgm}^{-1} \mathrm{~s}^{-1}$ ) and its divergence (in $\mathrm{kgm}^{-2} \mathrm{~s}^{-1}$ ). (a) wind speed and geopotential height at $500 \mathrm{hPa}$ for the larger APVI years; (b) as (a) but for the smaller APVI years; (c) as (a) but at 1000hpa; (d) as (b) but at 1000hPa; (e) vertical integral of water vapor flux and its divergence for the larger APVI years; (d) as (e) but for the smaller APVI years. 

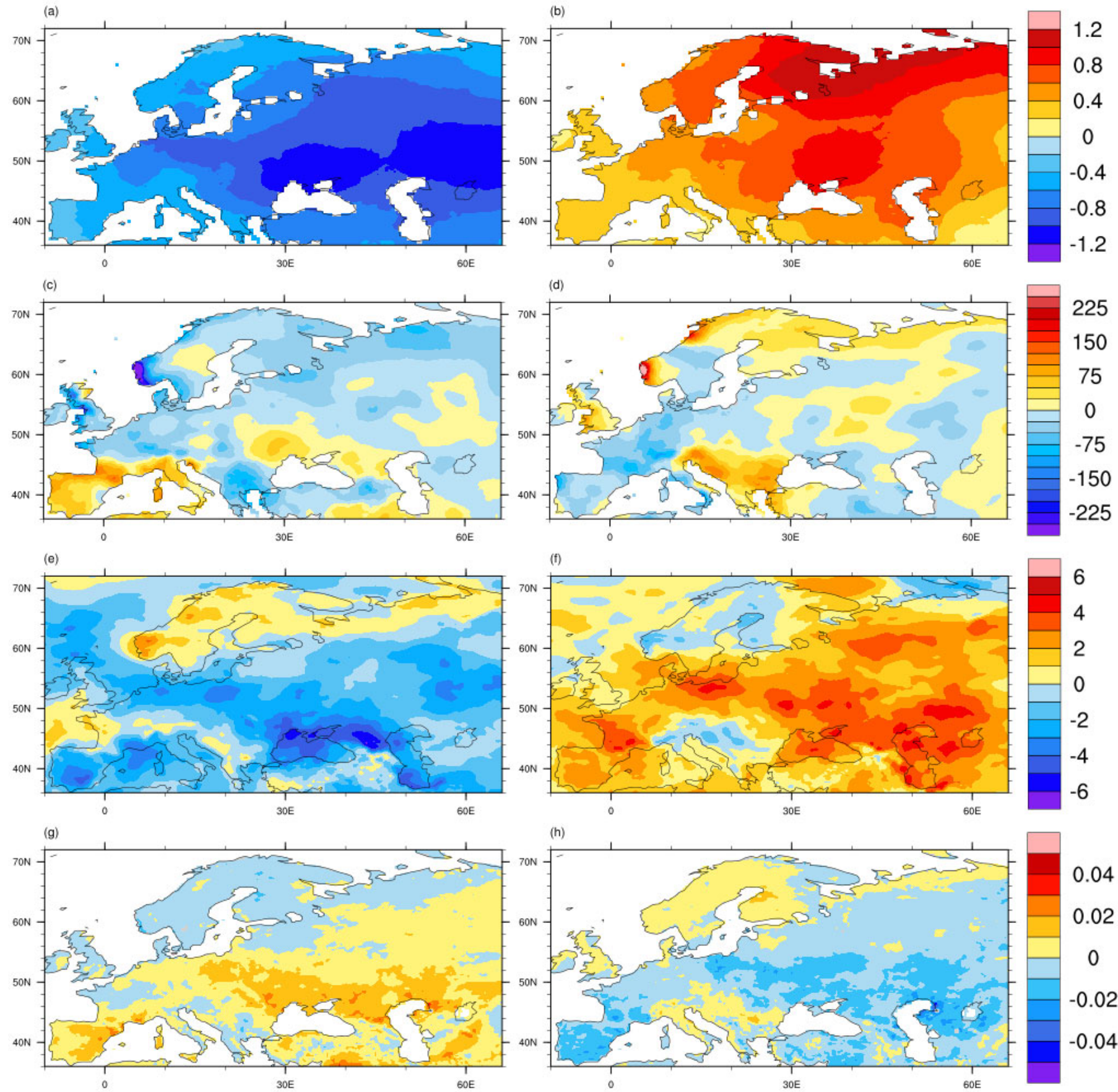

Figure 3 Composite analysis of yearly mean air temperature (in degree), yearly total precipitation (in $\mathrm{mm}$ ), surface solar radiation (in $10^{5} \mathrm{~J} / \mathrm{m}^{2}$ ) and volumetric soil water in 0-7 cm soil depth (in $\mathrm{m}^{3} / \mathrm{m}^{3}$ ) for the larger and smaller APVI years. (a) temperature for the larger APVI years; (b) temperature for the smaller APVI years; (c) precipitation for the large APVI years; (d) precipitation for the smaller APVI years; (e) solar radiation for the larger APVI years; (f) solar radiation for the smaller APVI years; (g) volumetric soil water for the large APVI years and (h) volumetric soil water for the smaller APVI years. 
(a)

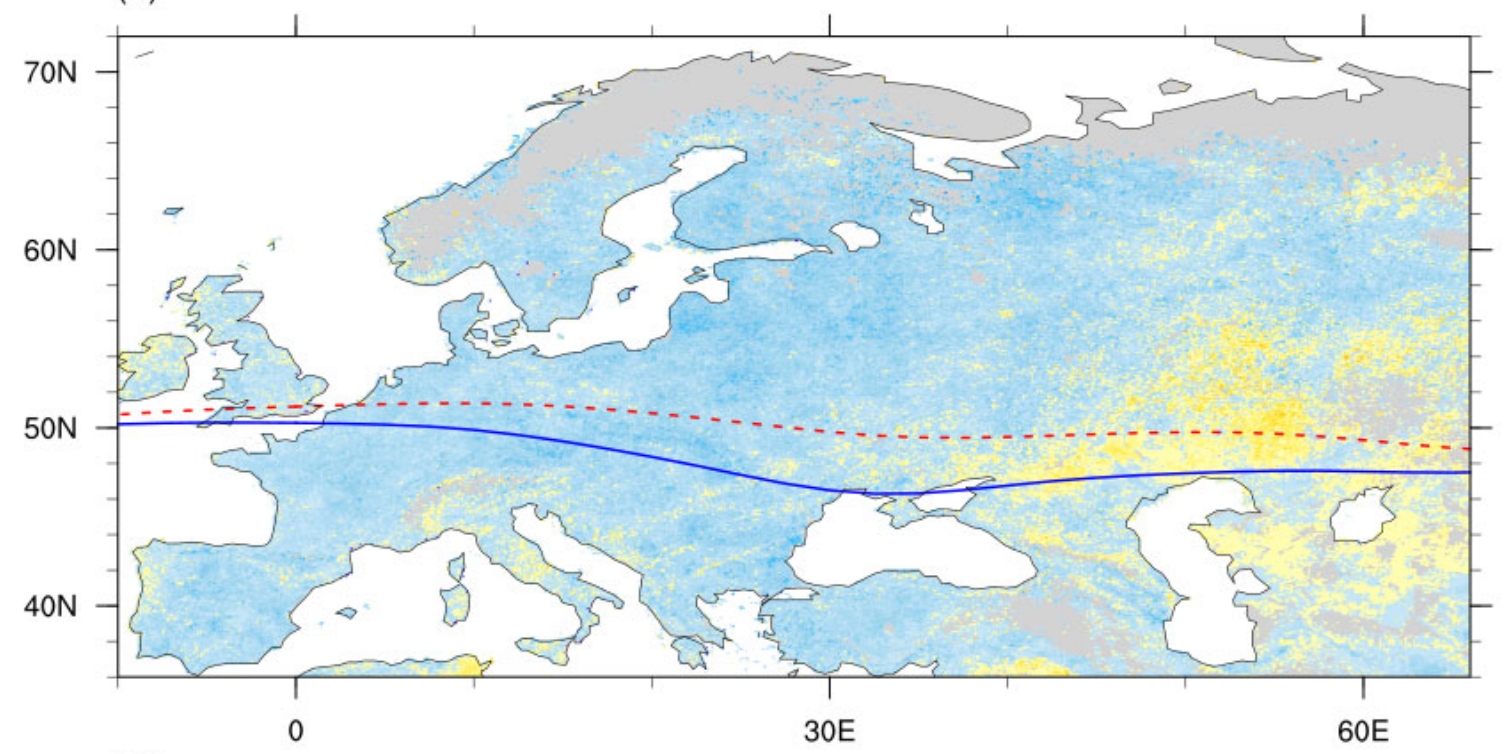

(b)

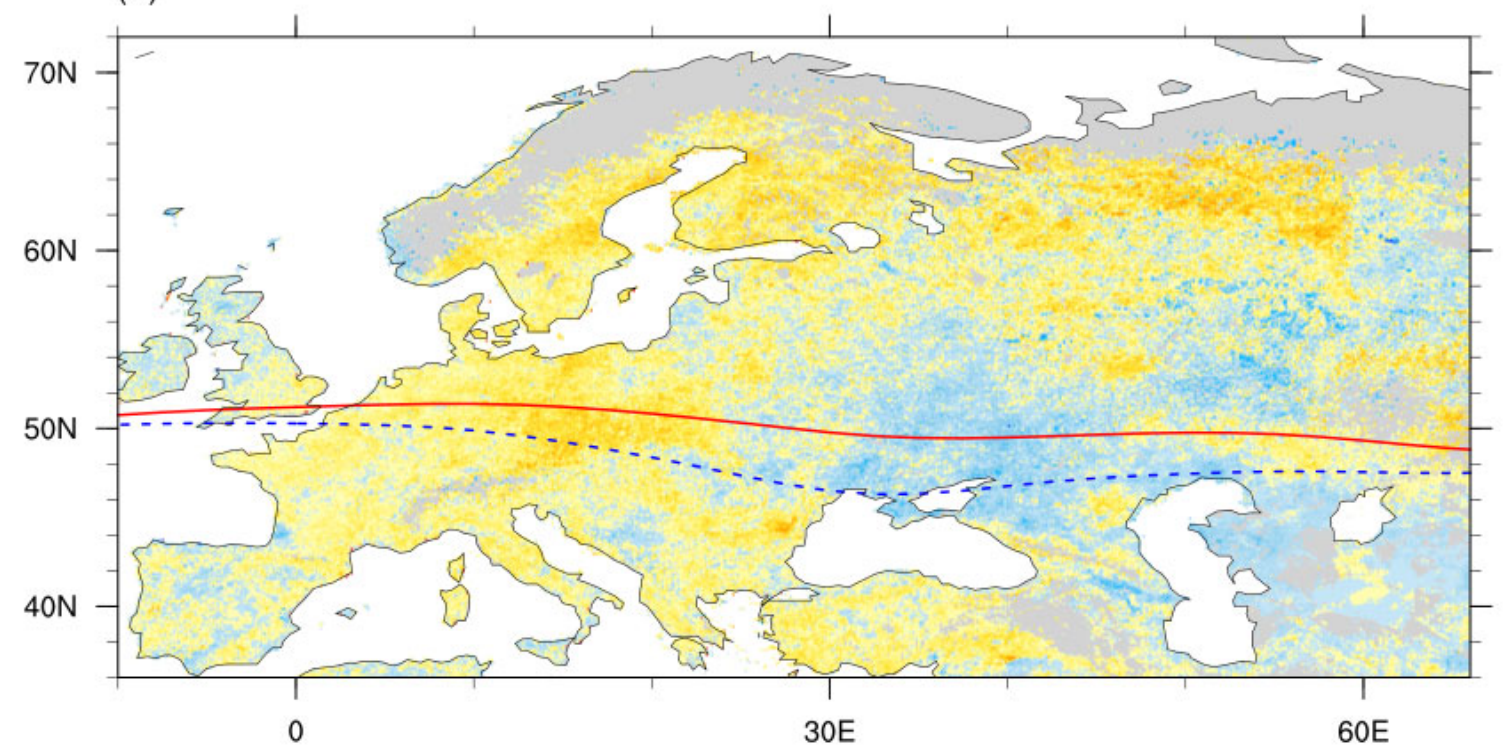

Figure 4 Spatial pattern of composite NDVI anomalies for the (a) larger and (b) smaller APVI years. The solid blue and red lines are the south boundary of the APV averaged over the larger and smaller APVI years, respectively. The dash blue line in (a) represents the mean south boundary of the smaller APV and the dash red line in (b) represents that of the larger APV. 
(a)

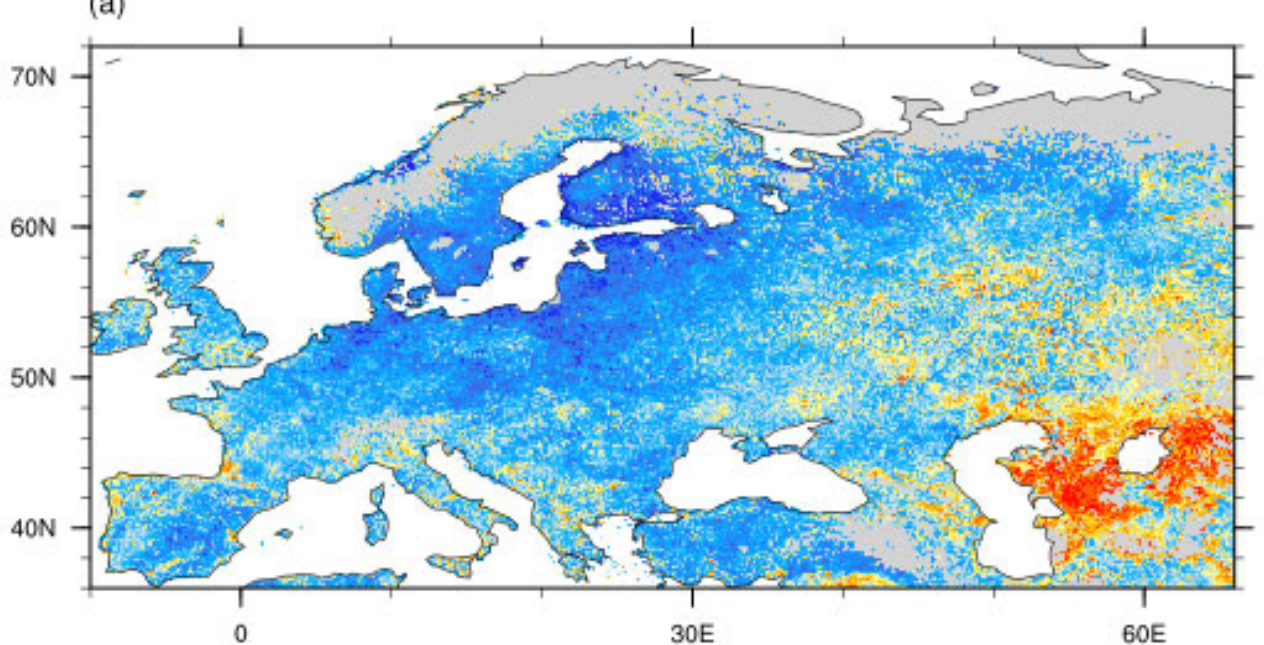

(c)

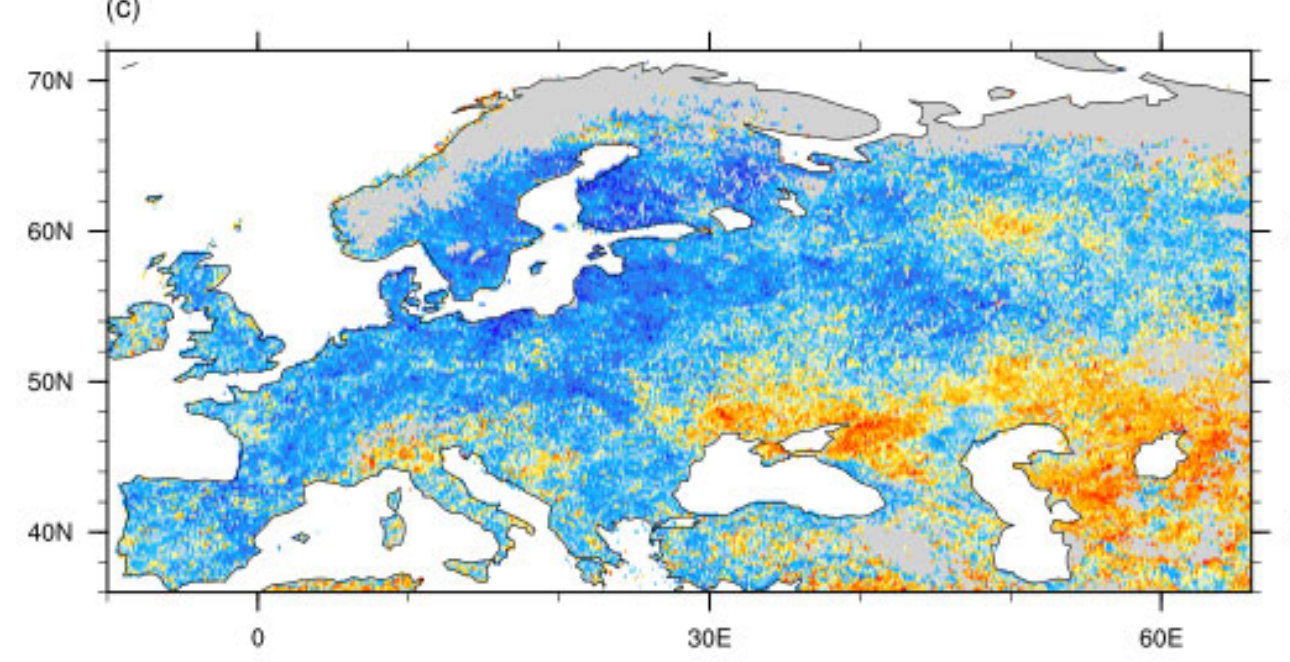

(b)

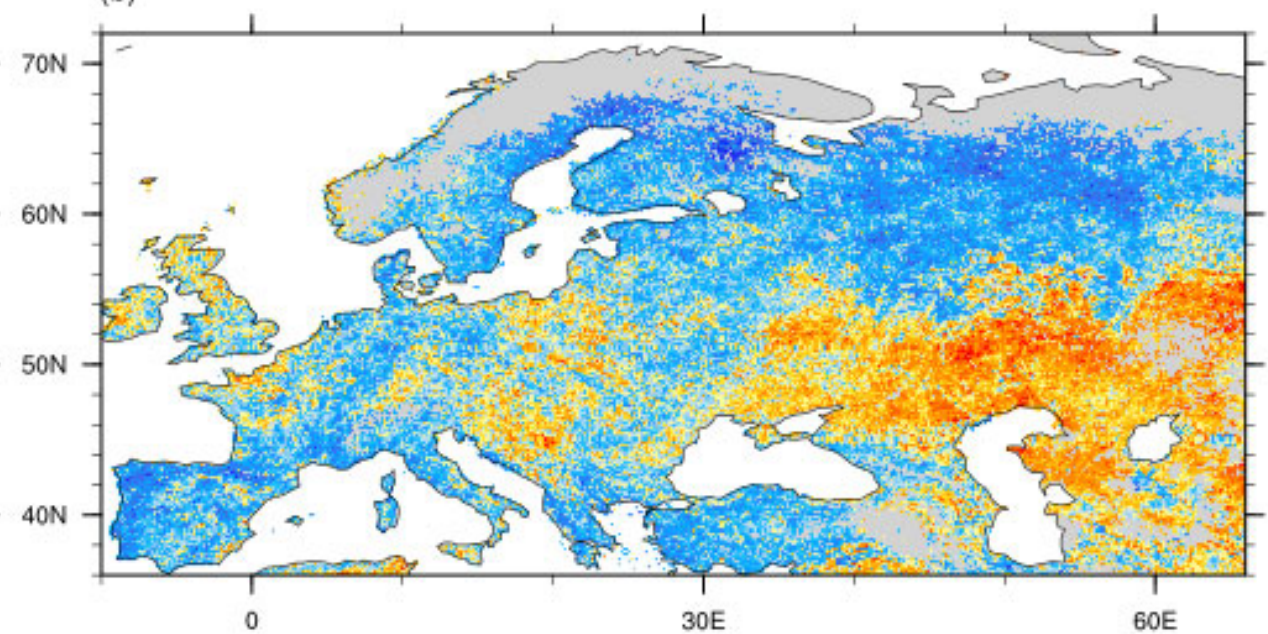

(d)

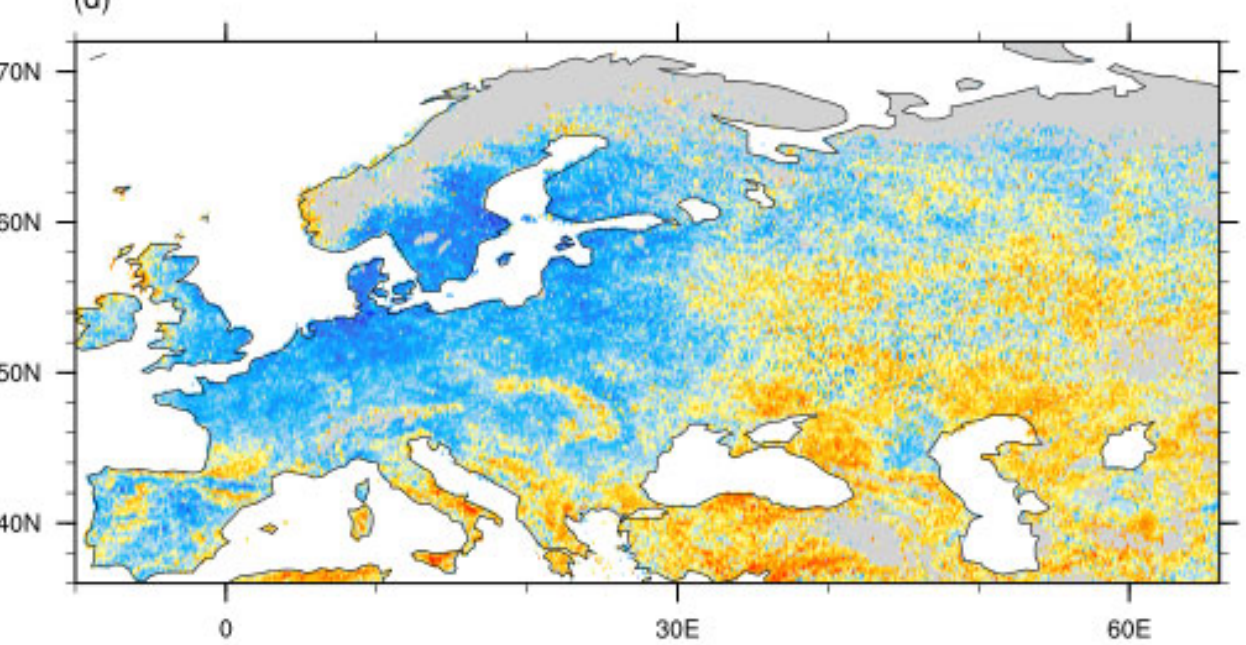

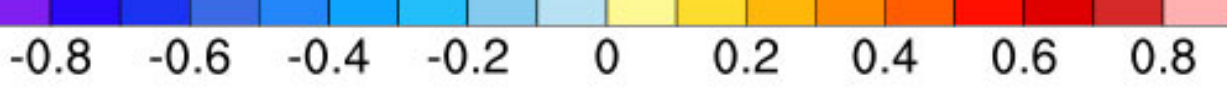

Figure 5 Spatial distribution of correlation coefficients between APVI and seasonal mean NDVI. (a) Spring (March to May); (b) Summer (June to August); (c) Autumn (September to November) and (d) winter (January, February and December). 

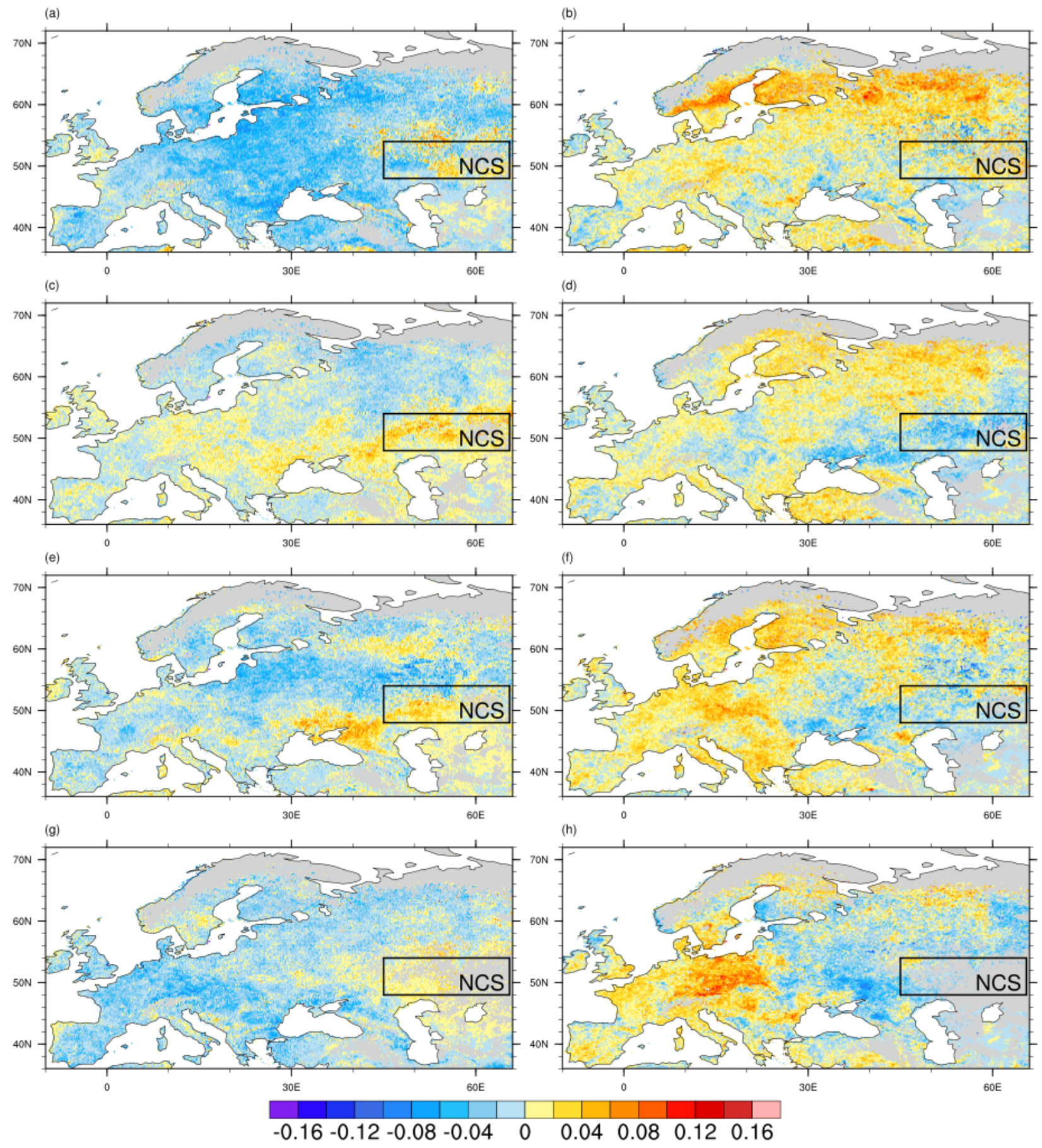

Figure 6 Spatial pattern of composite seasonal mean NDVI anomalies for the larger and smaller APVI years. (a) Spring (March to May) for the larger APVI years; (b) As (a) but for the smaller APVI years; (c) Summer (June to August) for the larger APVI years; (d) As (c) but for the smaller APVI years; (e) Autumn (September to November) for the larger APVI years; (f) As (e) but for the smaller APVI years; (g) Winter (January, February and December) for the larger APVI years and (h) as (g) but for the smaller APVI years. 
(a)

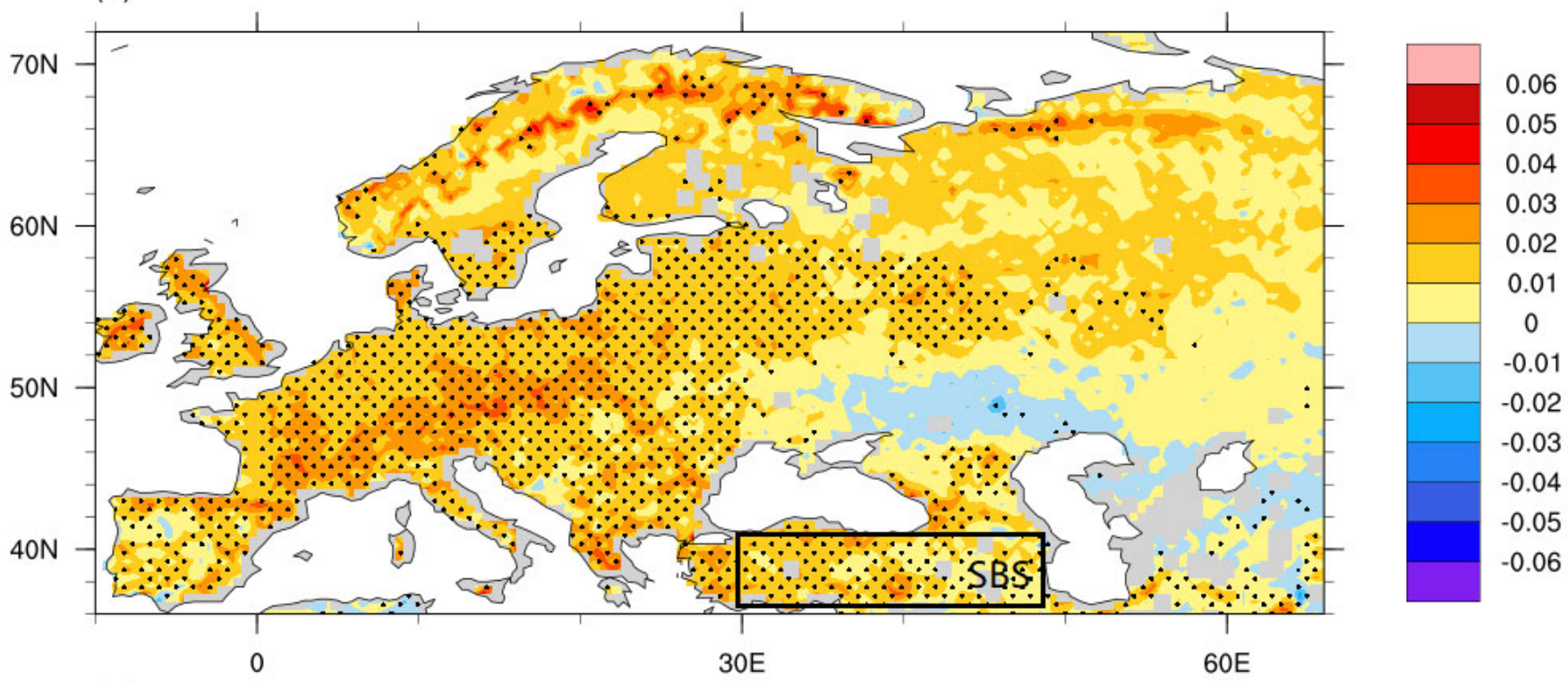

(b)

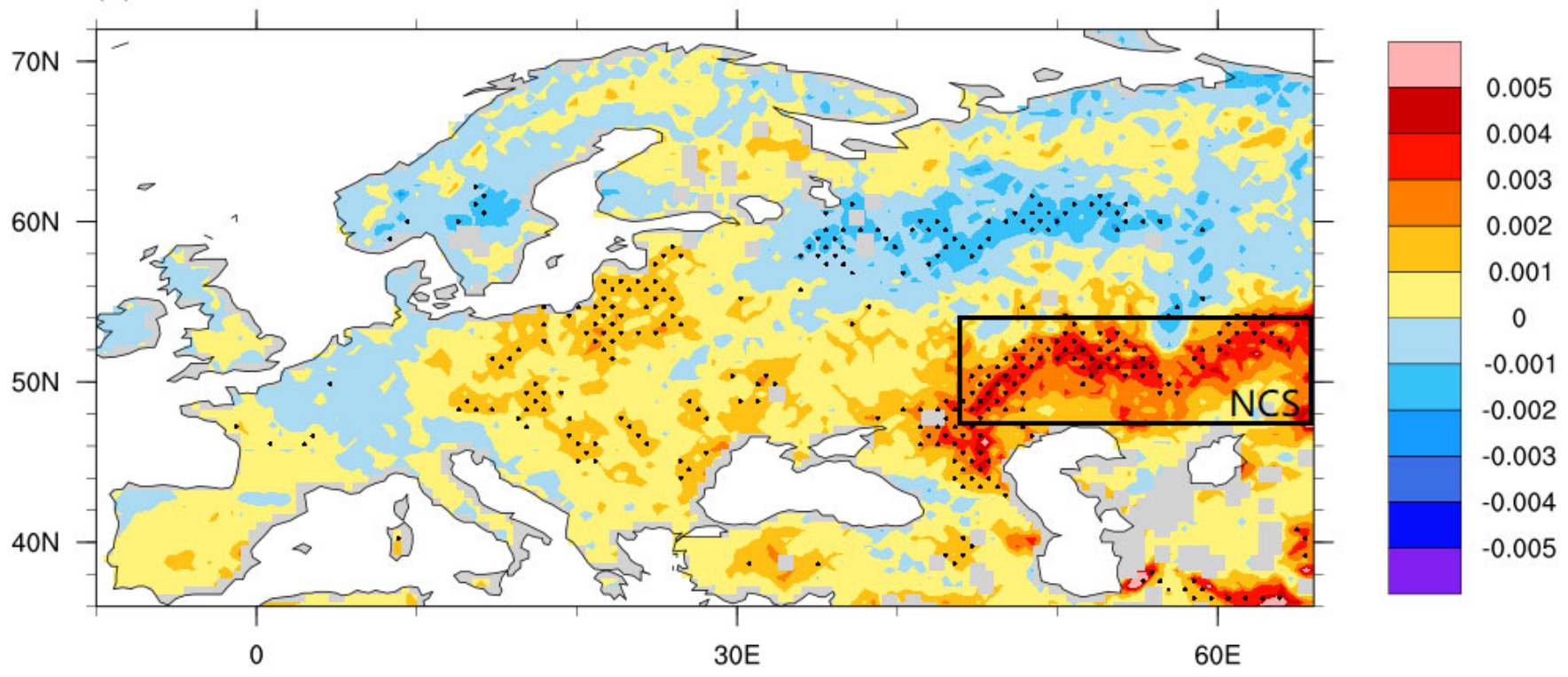

Figure 7 Spatial distribution of NDVI sensitivity coefficients for (a) temperature and (b) precipitation. Regions passed 95\% confidence level is masked by black points. 


\section{Supplement Figures}
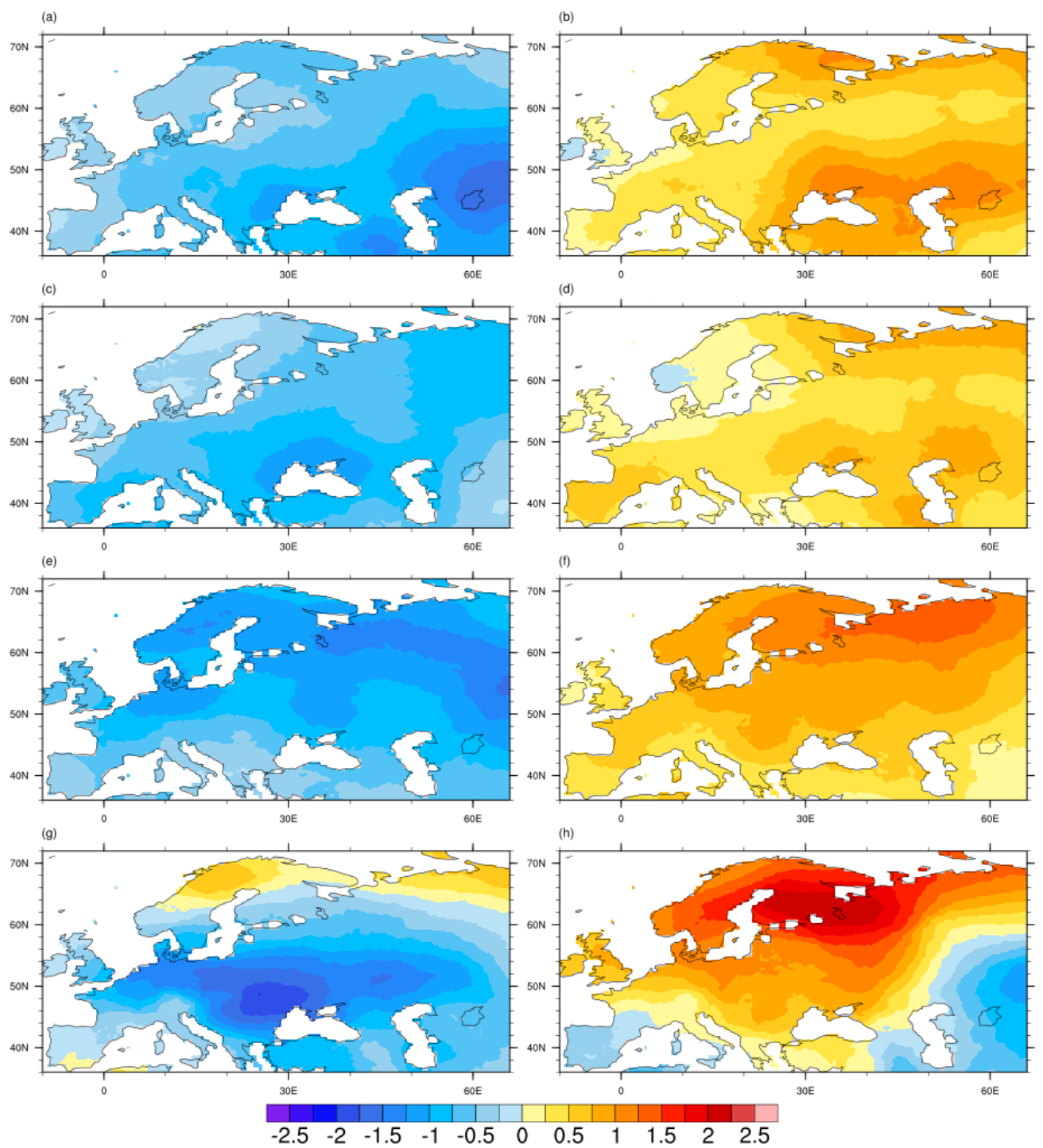

$\begin{array}{lllllllllll}-2.5 & -2 & -1.5 & -1 & -0.5 & 0 & 0.5 & 1 & 1.5 & 2 & 2.5\end{array}$

Figure S1 Spatial pattern of composite seasonal mean air temperature (in degree) for the larger and smaller APVI years. (a) Spring (March to May) for the larger APVI years; (b) As (a) but for the smaller APVI years; (c) Summer (June to August) for the larger APVI years; (d) As (c) but for the smaller APVI years; (e) Autumn (September to November) for the larger APVI years; (f) As (e) but for the smaller APVI years; (g) Winter (January, February and December) for the larger APVI years and $(\mathrm{h})$ as $(\mathrm{g})$ but for the smaller APVI years. 

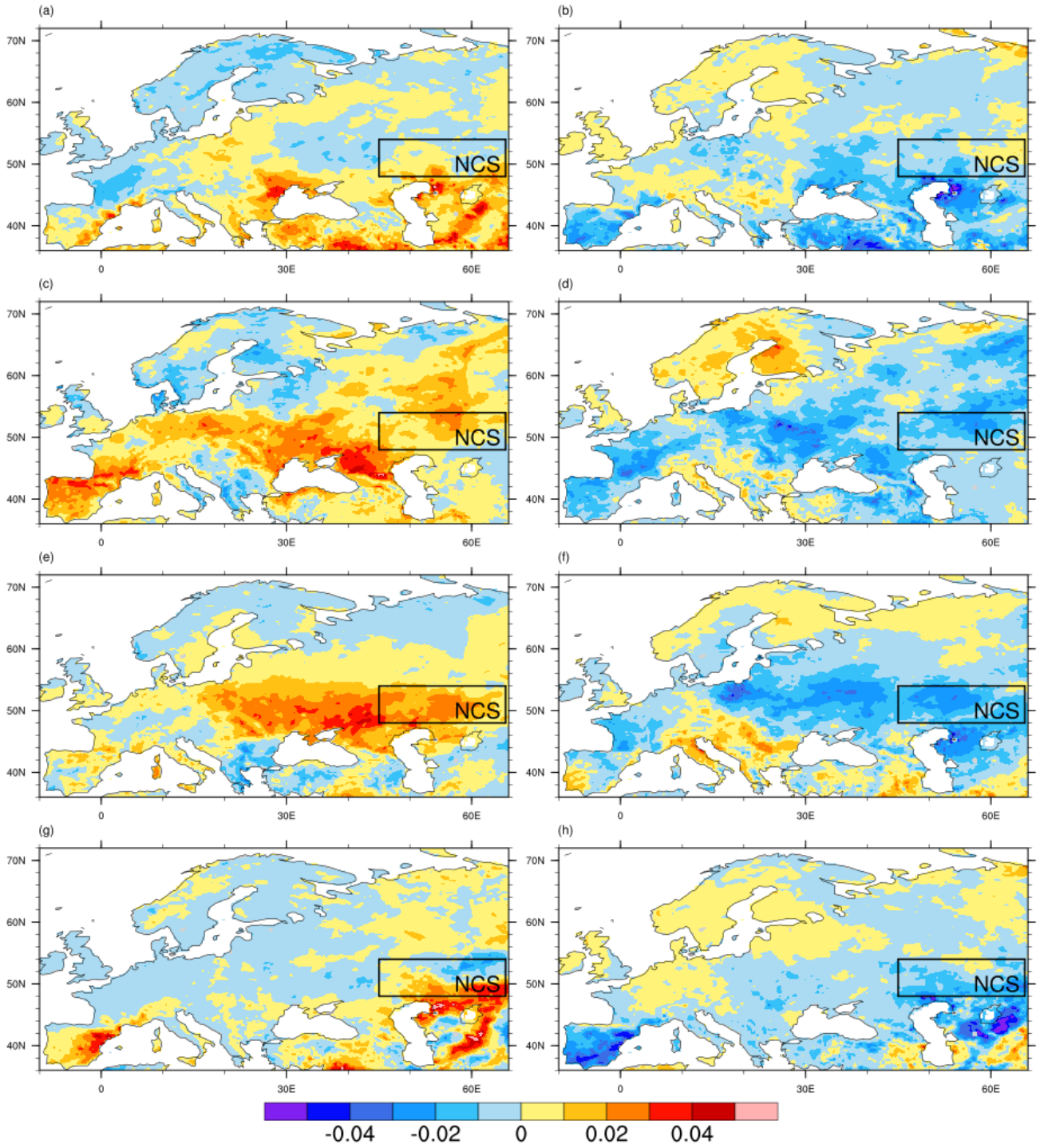

Figure S2 Spatial pattern of composite seasonal mean volumetric soil water content in the 0$7 \mathrm{~cm}$ soil depth $\left(\right.$ in $^{3} / \mathrm{m}^{3}$ ) for the larger and smaller APVI years. (a) Spring (March to May) for the larger APVI years; (b) As (a) but for the smaller APVI years; (c) Summer (June to August) for the larger APVI years; (d) As (c) but for the smaller APVI years; (e) Autumn (September to November) for the larger APVI years; (f) As (e) but for the smaller APVI years; (g) Winter (January, February and December) for the larger APVI years and (h) as (g) but for the smaller APVI years. 

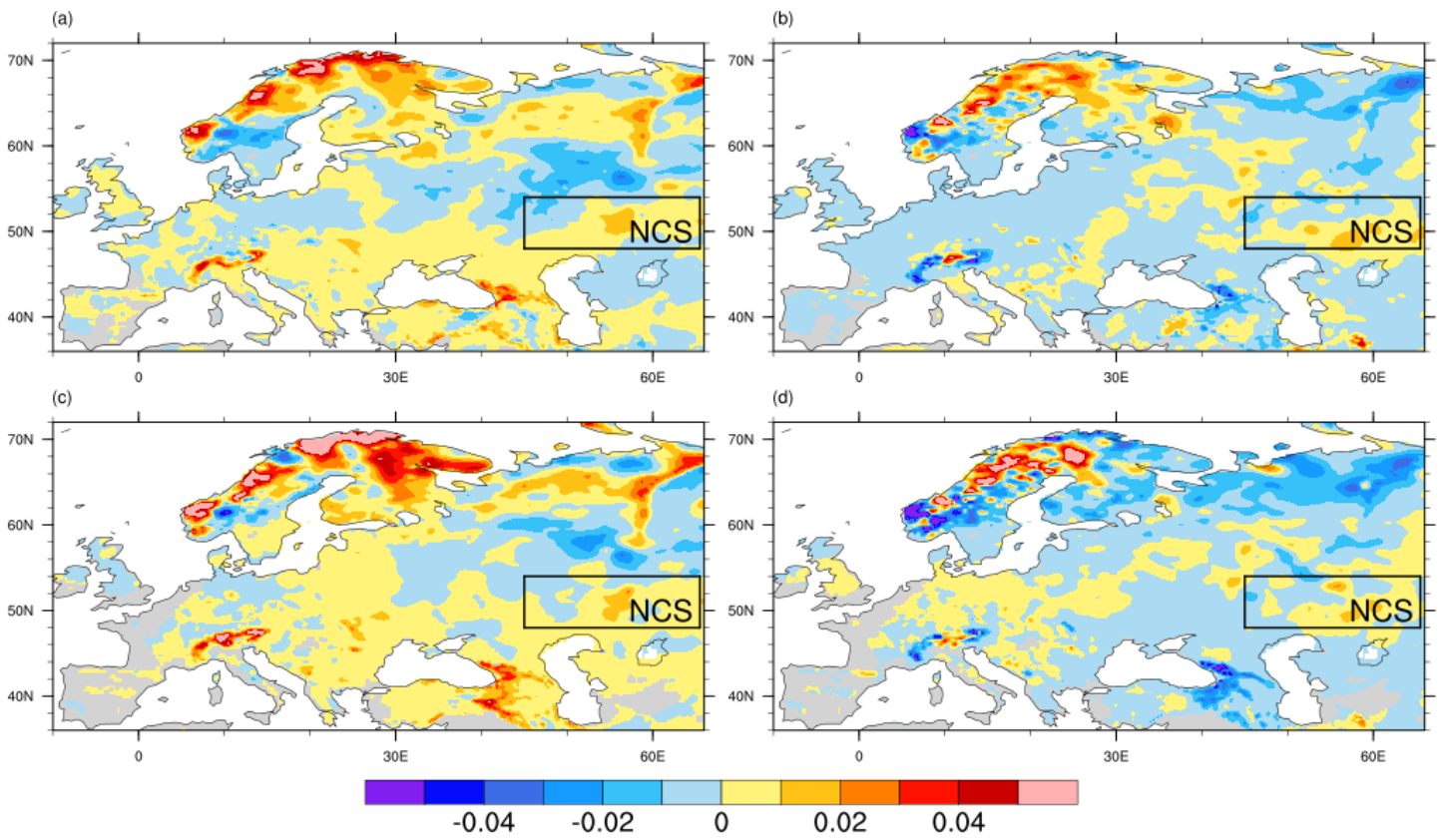

Figure S3 Spatial pattern of composite seasonal snow depth (in m) for the larger and smaller APVI years. (a) Winter (January, February and December) for the larger APVI years; (b) As (a) but for the smaller APVI years; (c) Spring (March to May) for the larger APVI years; (d) As (a) but for the smaller APVI years. 